\title{
Automatic Bridge Monitoring System Using IoT
}

\author{
SharmikhaSree.R ${ }^{\mathrm{a}, 1}$, Meera. $\mathrm{S}^{\mathrm{b}}$, Deepika. ${ }^{\mathrm{b}}$, DivyaS $^{\mathrm{c}}$, Priyadarshini V S ${ }^{\mathrm{c}}$ \\ ${ }^{a, b}$ Assistant Professor, Dept of CSE, Sri SaiRam Engineering College, Chennai, India \\ ${ }^{c}$ UG Scholar, Dept of CSE, Sri Sai Ram Engineering College, Chennai, India
}

\begin{abstract}
Monitoring the bridge is very important as a poor bridge may lead to many accidents. Therefore it needs a system to monitor the strength or stability of the bridge in order to avoid any failures. Cracks may occur due to accidents or overload in the bridges which will be identified by the mems sensor. The bridge monitoring system is significant for monitoring bridges or flyovers. The aim is to develop an IOT based bridge monitoring system that will automatically detect the cracks and checks if there is an increase in vibration. Different sensors are used for monitoring. It also monitors the light in the bridge which is very important especially during nighttime. It also checks if the heat of cables in bridges increases which may cause fire and also checks the fire.
\end{abstract}

Keywords: MEMS sensor, Vibration sensor, Fire sensor, GSM.

\section{Introduction}

Is bridge really important? what happens if there is the absence of a bridge in a heavy traffic area? Yes, there is a need for the bridge without which there will be severe consequences. Bridge is very important as poor bridge leads to many accidents. Therefore it needs a system to monitor the health of bridge which is being one of the diagnostic tools that prevents the causes from progression and avoid any failure. It identifies the crack that occurs due to accidents or overload in the bridge. It is significant for monitoring bridges and flyovers and it automatically detects the cracks and if checks and if any increase in vibration. It also monitors the light in the bridge especially during nighttime and also checks if the heat of cable in the bridges increases if may cause fire and also checks the fire.

\section{Related work}

There are various works in this field of study. The first reference is from[1] where the author uses a wireless sensor network for bridge monitoring. For fire detection, there are lot of methods especially from[2] where fire detection is done using a fire sensor.

${ }^{1}$ Sharmikra Sree R, Assistant Professor, Dept of CSE, Sri Sai Ram Engineering College, Chennai, India. Email:sharmikasree.cse@sairam.edu.in ${ }^{1}$ 
The paper[3] is for vibration detection Where vibration in the bridge is monitored. In paper [4] the author uses a mems sensor for crack monitoring. It works by angle detection. $\operatorname{In}[5]$ the author monitors the strain of the bridge which may cause due to overload [6-8].

\section{Proposed System Methodology}

In this project, we use a mems sensor to detect cracks. Mems sensor works by measuring the angle, so even if a small crack occurs there will be a change in angle. Even if there is a slight change in the angle it will indicate us the next second which will be quicker and better. The vibration sensor senses any vibration in the bridge. Normally all kinds of accidents cause some vibration. So vibration sensor monitors the occurrence of vibration. LDR sensor is used to monitor the bridge lights. Here temperature sensor is also used to monitor the heat in the bridge, as an increase in heat of cables in the bridge can lead to fire accidents, and a fire sensor is used to detect fire.

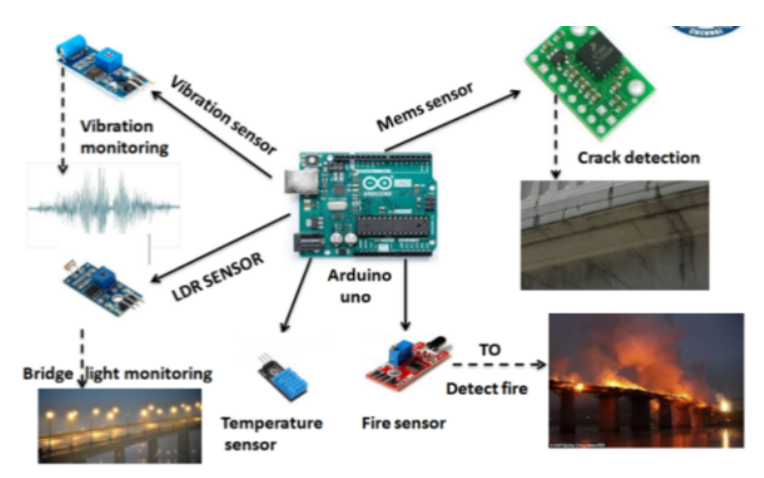

Figure1.Bridge Monitoring System

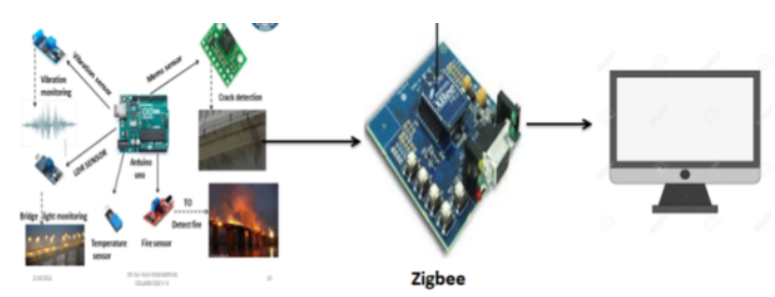

Figure 2.Storing the values in a PC.

\section{Design Module}

\subsection{Detecting the image of the cracks is given below}

Micro Electro Mechanical Systems(MEMS) basically works with axis and measuring the angles. The X, Y, Z-axis angles are fixed. Cracks occur due to accidents, poor maintenance, or even due to heavy load and overstrain. If any type of crack occurs 
there will be some change in the angles. If any change occurs the mems sensor will sense the change in angle and indicates using a buzzer.

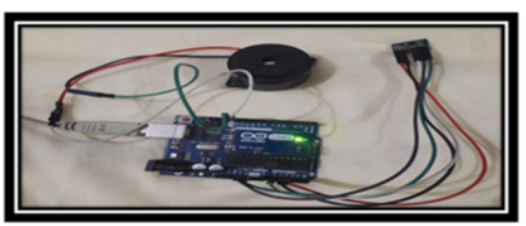

Figure 3. Micro Electro Mechanical Systems

\subsection{Vibration observing and light monitoring image is given below:}

First, for observing vibration, a vibration sensor is used. If vibration occurs beyond the threshold value, the LED indicator indicates the user. The values are transferred to the user through a wireless communication Zigbee. Then to monitor the bridge lights LDR sensor is used. This sensor works by digital signals. If there is some problem with bridge lights it will indicate the user by GSM message.

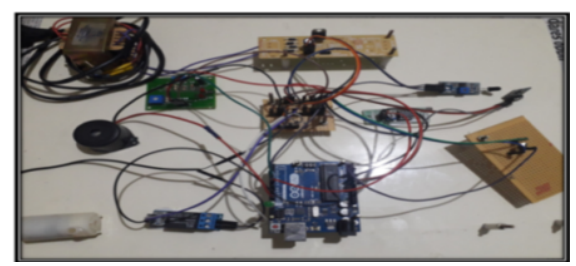

Figure 4. Zigbee

\subsection{Heat checking and fire sensing}

Heat checking is done by the temperature sensor. It senses any increase in heat and indicates the user by GSM message. A fire can be detected using a fire sensor. If there is any occurrence of fire the sensor senses it and immediately the pump motor is turned on.

\subsection{Wireless data transfer}

The readings and values detected using all the sensors are transmitted using a wireless transmitter Zigbee to the pc. The user can get the values from the pc.

\subsection{Hardware components}

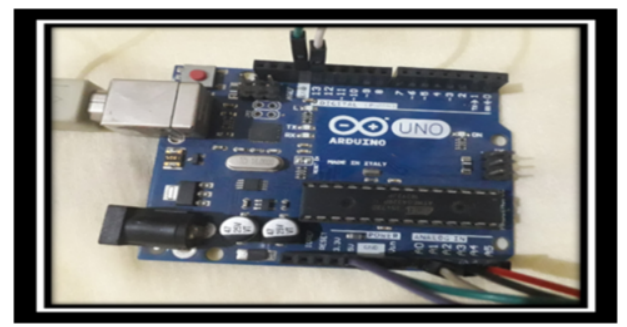

Figure 5. Arduino UNO 
It comes under an open-source electronics platform based and it is easy-to-use hardware and software. To read inputs - light on a sensor with the help of Arduino boards. It is a great tool for developing interactive objects, by taking inputs from a variety of sensors or switches and controlling a variety of lights, motors, and other outputs. They can be connected to a computer using USB or the projects can be standalone.

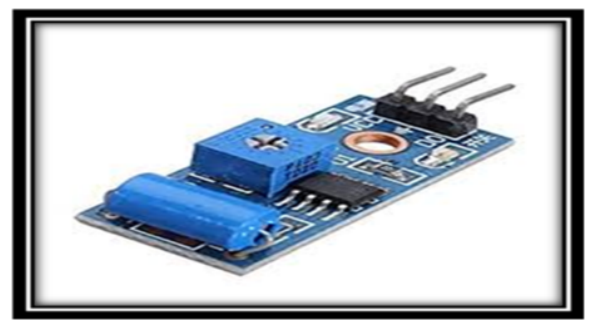

Figure 6. Vibration sensor

It is a device to measures the frequency of vibration in a given system, piece of equipment, or machine. Where these measurements can be used to detect imbalances or other issues in the asset.And to predict the future defect. If a vehicle meets with an accident immediately Vibration sensors detect the signal. Where these sensors are flexible devices that are used for measuring various processes. It measures the changes within acceleration, pressure, temperature, force.

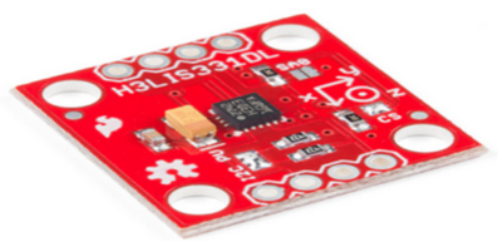

Figure 7. Mems Sensor

It is known as a Micro-Electro-Mechanical System. It is a process or technology used to create tiny integrated devices or it is a system that combines electrical and mechanical components. It provides the convenient features that you can get with any other sensor line such as analog voltage, current, and digital output options. To detect the cracks using a mems sensor by measuring the angle deviation continuously and to give an alert.

\section{Conclusion}

The proposed system "Automatic Bridge Monitoring System Using Iot", is useful to society as it checks the strength of the bridge, anyvariations intimated and save the lives of passengers on the bridge, has been successfully implemented and testing is done and verified. In this system, we use many sensors like a mems sensor, vibration sensor, fire sensor, temperature sensor. So, it is very beneficial. Mostly these sensor used separately in the existing system but we have accommodated all sensors together, with the addition of GSM, LDR sensor, pump motor .where the GSM message can be 
transacted directly to the Municipal Corporation to rectify the problem easily and So, it is being efficient for diagnosing to prevent from undesirable consequence. It is a preventive treatment for failure due to accidents.

\section{References}

[1] Seno AdiPutra;BambangRiyantoTrilaksono; Muhammad Riyansyah; Dina Shona Laila, Multiagent Architecture for Bridge Capacity Measurement System Using Wireless Sensor Network and Weight in Motion ,IEEE Transactions on Instrumentation and Measurement vol:70, 2020

[2] Yanyan Fan; Zhenzhen Yang; Ziqi Li; Research on Fire Risk Assessment and Control Methods for Urban Bridges Based on Fuzzy-Bn . 12th International Conference on Measuring Technology and Mechatronics Automation (ICMTMA), 2020

[3] Thomas J. Matarazzo ; Paolo Santi; Shamim N. Pakzad; Kristopher Carter; Carlo Ratti; Crowdsensing Framework for Monitoring Bridge Vibrations Using Moving SmartphonesSci. (ICAMS), 2010 IEEE Journal, vol. 106, 2018.

[4] Cheng-Ta Chiang.Design of a CMOS MEMS Accelerometer Used in IoT Devices for Seismic. IEEE Int. Detection. Conf., vol. 8, 2018.

[5] YuePeng-cheng, Research on the strain acquisition system of expressway bridge. First,International Conference on Electronics Instrumentation \& Information System (EIIS).vol: 70,2017.

[6] Ambeth Kumar.V.D .Precautionary measures for accidents due to mobile phone using IOT.Clinical eHealth, Volume 1, Issue 1, March 2018, Pages 30-35.

[7] Ambeth Kumar.V.D (2018).Novel Wireless Sensing System For The Welfare Of Sewer Laborers. Healthcare Technology Letters (IET) Volume 5, Issue 4, p. $107-112$.

[8] Ambeth Kumar.V.D, Saranya.G , D.Elangovan, V.RahulChiranjeevi, V.D.Ashok Kumar.IOT Based Smart Museum Using Wearable Device. Lecture Notes in Networks and Systems, Vol.55, pp: 33-42, 2018

[9] K. Nanagasabapathy; G. Harish; O. I. Allen Sebastian; N. Sowrabh Chandra; V. D. Ambeth Kumar," Validation system using smartphone luminescence", IEEE International Conference on Intelligent Computing, Instrumentation and Control Technologies (ICICICT), Pages: 235 -239, 2017. DOI: 10.1109/ICICICT1.2017.8342566

[10] B. Aravindh; V.D.Ambeth Kumar; G. Harish; V. Siddartth, " A novel graphical authentication system for secure banking systems", IEEE (ICSTM), Pages: 177-183, 2-4 Aug. 2017, DOI: 10.1109/ICSTM.2017.8089147

[11] R. Subha Shini et.al., " Recurrent Neural Network based Text Summarization Techniques by Word Sequence Generation",IEEE International Conference on Inventive Computation Technologies (ICICT), 2021, DOI: 10.1109/ICICT50816.2021.9358764

[12] V.D.Ambeth Kumar et.al,, "An Efficient Security System for Data base Management from Illegal Access, IEEE International Conference on Wireless Communications, Signal Processing and Networking, 2016. DOI: 10.1109/WiSPNET.2016.7566252 